\title{
A Novel Nib-Like Design for Microfabricated Nanospray Tips
}

\author{
Séverine Le Gac, Cécile Cren-Olivé, and Christian Rolando \\ Laboratoire de Chimie Organique et Macromoléculaire, UMR CNRS 8009, Université des Sciences et Technol- \\ ogies de Lille Cité Scientifique, Villeneuve d'Ascq, France
}

\section{Steve Arscott}

Institut d'Electronique de Microélectronique et de Nanotechnologie and Laboratoire de Chimie Organique et Macromoléculaire, UMR CNRS 8009, Université des Sciences et Technologies de Lille Cité Scientifique, Villeneuve d'Ascq, France

We present here novel tips for nanoelectrosray ionization-mass spectrometry (ESI-MS) applications. These ionization sources have a planar geometry in the shape of a nib. Their functioning is based on a principle much akin to that of a fountain pen in that fluids are actuated by capillarity. Once a voltage is applied, an electrospray is formed at the nib tip. The nib fabrication relies on micromachining techniques using the epoxy-based negative photoresist SU-8 and a double exposure photolithographic process. Two types of nib-like sources were fabricated; they were made either conductive by metallization with a nickel layer or non-conductive but hydrophilic by covering them with a $\mathrm{SiO}_{2}$ layer. In the latter case, the $\mathrm{HV}$ was applied via a Pt wire inserted into the reservoir feature of the nib. The nib-like sources were tested on an ion trap mass spectrometer using Gramicidin S samples at concentrations as low as $1 \mu \mathrm{M}$ and ionization voltages as low as $1.2 \mathrm{kV}$. We have observed a good overall stability of the spray during the tests with no marked decrease in the signal intensity even under extreme conditions. (J Am Soc Mass Spectrom 2004, 15, 409-412) (C) 2004 American Society for Mass Spectrometry

$\mathrm{T}$ This paper deals with the use of microtechnology for the fabrication of electrospray ionization emitter tips. In this context, the smaller the dimensions, the better the performances. Nonetheless, the microfabricated emitter tips reported in the literature hardly meet nanospray criteria. Needle-like microfabricated emitter tips exhibit dimensions larger than conventional nanotips [1-5] while planar devices resulting from microtechnology techniques are not sharp enough and work under ESI rather than nanoESI conditions [6-10]. We aim at the design, fabrication and testing of an ESI emitter tip with small features which works under nanospray conditions, i.e., an ionization voltage of the order of $1 \mathrm{kV}$. We present a novel approach to the fabrication of a tip with a nib-like shape using the epoxy-based negative photoresist SU-8. The functioning of these micro-nibs is much akin to that of a simple fountain pen with a reservoir feature and a capillary slot guiding the fluid towards the nib tip via capillary action and thus towards the MS inlet.

Published online January 15, 2004

Address reprint requests to Dr. C. Rolando, Université des Sciences et Technologies de Lille (Lille 1), Bâtiment C4, 2ème étage, UMR CNRS 8009, Chimie Organique et Macromoléculaire, 59655 Villeneuve d'Ascq Cedex, France. E-mail: Christian.Rolando@univ.lille1.fr

\section{Experimental}

\section{Preparation of the Samples}

The peptides (Gramicidin S, Angiotensin I) and solvents used for the MS experiments were purchased from Sigma (L'Isle d'Abeau, France). Stock solutions of peptides were prepared in deionized water. Test solutions were prepared by diluting a $0.1 \mathrm{mM}$ peptide stock solution using a MeOH: $\mathrm{H}_{2} \mathrm{O}$ solution acidified with $0.1 \%$ formic acid.

\section{Micro-Nib Fabrication}

The micro-nibs are composed of two parts: A main SU-8 feature which supports the micro-nib and a membranelike feature including a capillary slot leading the fluid to the nib tip by capillary action. The main SU-8 feature acted as a reservoir for loading the samples for the MS test.

The fabrication of the micro-nibs is described in Figure 1. A $400 \mu \mathrm{m}$ layer of SU-8 2075 was deposited on the $\mathrm{Si}$ wafer using standard spin-coating techniques (Step 1). A multilayered membrane-like structure was then formed using a so-called $21 / 2 \mathrm{D}$ fabrication technique which relies on a double photolithography of the SU-8 using two photomasking and exposure steps. The 
1)

2)
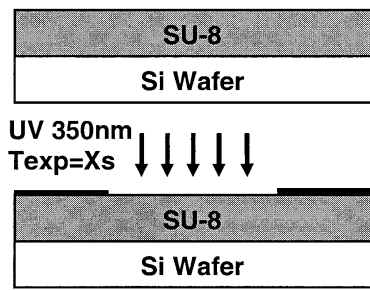

3)

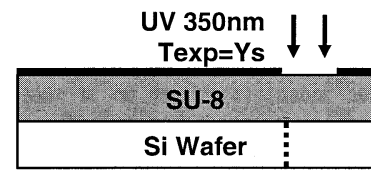

4)

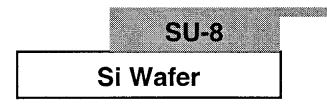

Photomask 1

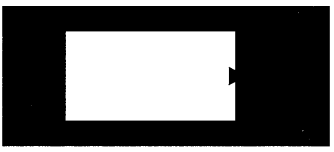

Photomask 2
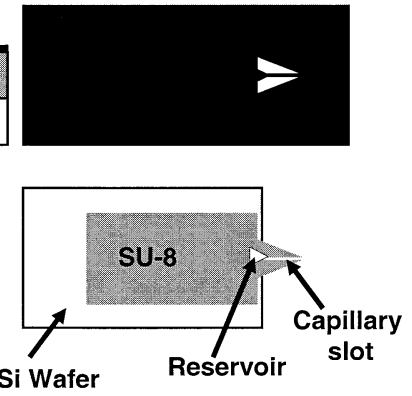

Figure 1. Fabrication steps 1-4 for the micro-nibs; side views (on the left) and top views (on the right). Starting from a Silicon wafer (100) covered with a $400 \mu \mathrm{m}$ thick SU-8 layer (1), a double exposure technique is used to pattern the photoresist: the first exposure with an exposure time (Texp Xs) allows for forming the main part of the nib structure (2) whilst the second exposure (Texp Ys) is shorter and allows for forming the membrane-like tip structure (3). The SU-8 is then developed so as to remove the non-exposed or non polymerized material; the $\mathrm{Si}$ wafer is also cleaved (dashed line in c) so as to free the micronib tip (4).

first step involved the formation of the main pillar of the system (Step 2) with an Xs exposure time (Texp) chosen so that the whole SU-8 thickness was polymerized. The membrane-like feature with the capillary slot and the point-like structure (Step 3) was formed in the second step with a Ys shorter exposure time so that only the upper resist layer was polymerized. A photoresist development step released the membrane-like feature from the Si wafer by removing the non-polymerized resist (underneath the nib tip and unexposed zones). Finally, the micro-nib was made to hang over the edge of the Si wafer (Step 4) by cleaving the silicon wafer along one of its crystallographic planes. The first batch of micro-nibs were made conductive via a nickel coating (500 A) using RF sputtering while the second batch was coated with a $\mathrm{SiO}_{2}$ layer $(1000 \AA)$ via plasma enhanced chemical vapor deposition (PECVD). The slot width was of $20 \mu \mathrm{m}$ with a membrane depth at the tip of around $30 \mu \mathrm{m}$; the length of the nib tip was approximately of $500 \mu \mathrm{m}$.

\section{Instrumentation}

The nib sources were tested on a LCQ Deca XP+ Ion Trap mass spectrometer (Thermo Finnigan, San Jose, CA). The nib-like structures were mounted on an $x y z$ micro-positioning translational stage. For hydrophilic nibs, a rigid platinum wire (diameter $=125 \mu \mathrm{m}$ ) was manually placed into the reservoir; this wire was used as an electrical contact between the metallic zone of the

standard needle tip holder where HV is supplied and the liquid sample. A few micro-liters of the sample were dropped into the nib reservoir feature and capillary action was seen to result in the test liquid being present at the nib tip. The voltage was then applied on the liquid; we used voltage values in the $1.2-2.5 \mathrm{kV}$ range for testing these prototypes. A camera mounted on the ion trap mass spectrometer allowed us to directly visualize the formation of the Taylor cone and the liquid flow in the capillary slot. Comparison tests were carried out using a medium borosilicate glass tip coated with a gold/palladium alloy from Protana (Odensee, Denmark) and having a $1 \mu \mathrm{m}$ i.d. (ES 380). This tip was loaded with a $1 \mu \mathrm{M}$ sample. The ionization was operated at $1 \mathrm{kV}$ without any pressure assistance. The total ion current (TIC) signal was acquired for $2 \mathrm{~min}$ and the resulting mass spectrum was plotted as an average over this period using appropriate software (Excalibur, Thermo Finnigan, San Jose, CA).

\section{Results and Discussion}

\section{Micro-Nib Microfabrication}

The prototypes presented here were designed to assess the feasibility of such emitter tips and their compatibility and functioning in ESI experiments.

\section{Electrospray Performance}

SU-8 is neither strongly hydrophilic nor strongly hydrophobic; the contact angle is around $80^{\circ}$ for pure water on SU-8. As expected, the capillary effect ensures the moving of the test solution (MeOH: $\left.\mathrm{H}_{2} 0,50: 50\right)$ towards the tip to fill in the slot, as seen after loading of the reservoir. A Taylor cone was observed under voltage application as shown on the pictures of a nib under (Figure 2) and without (insert in Figure 2) voltage. The MS tests were restricted by the volume of the reservoir. The test duration was dictated by the time required to consume the dropped volume, assuming a consumption rate of the order of $1 \mu \mathrm{L} / \mathrm{min}$, which needs improving.

The nickel coating on the first batch of nibs degraded under HV application after multiple-use, as is commonly observed for any emitter covered with a conductive layer. Conversely, the $\mathrm{SiO}_{2}$ coated nibs had a much longer life and more tests could be carried out using a single micro-nib. Thus, we will mainly focus on the experiments and results obtained with the latter hydrophilic sources. No release of the SU-8 resist was observed as chemical noise on the spectra. This was to be expected as the resist was in both cases covered by either $\mathrm{Ni}$ or $\mathrm{SiO}_{2}$. In addition, we did not observe any adsorption of the peptides on the nib. 


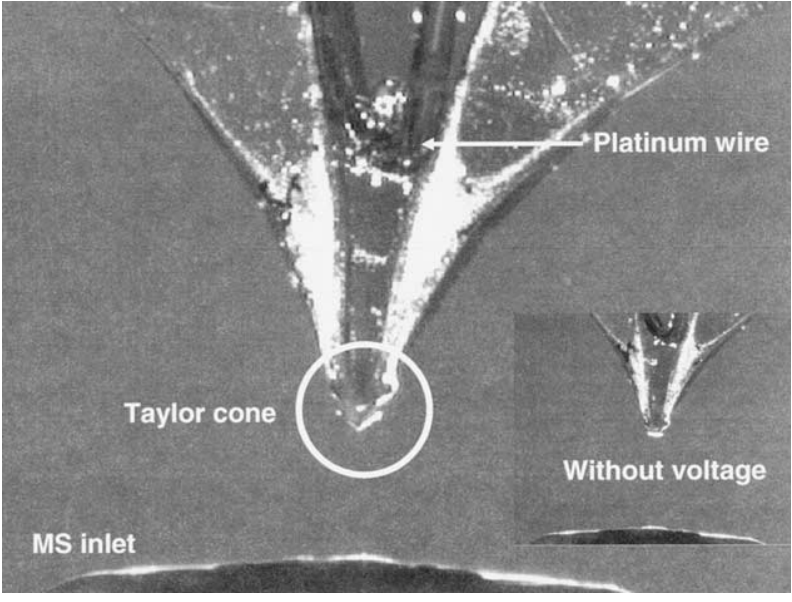

Figure 2. Photograph of the nib-like source in front of the ion trap mass spectrometer inlet; top view taken using the camera on the ion trap, with voltage and without voltage (in insert). Under HV supply, one can clearly see the Taylor cone. Note the capillary slot of the nib filled in with liquid and the platinum wire inserted in the reservoir for HV supply.

\section{MS Tests: TIC Signal Stability and Resulting Mass Spectra}

We tested Gramicidin S samples at 50 down to $5 \mu \mathrm{M}$ and HV supply was in the $1.2-2.5 \mathrm{kV}$ range. The total ion current (TIC) was recorded over a period of $2 \mathrm{~min}$. We observed stable signals, even with the lowest concentration down to a $1.2 \mathrm{kV} \mathrm{HV}$ value. There was no particular decrease in the signal intensity when decreasing either the HV value or the peptide concentration; Table 1 presents the TIC intensity measured in a series of tests. Figure 3 shows the TIC signal observed for a 20 $\mu \mathrm{M}$ Gramicidin S solution with an HV of $2.2 \mathrm{kV}$. A RSD value of $7.5 \%$ was calculated from this plot.

All spectra showed the $(\mathrm{M}+\mathrm{H})^{+}$as well as the $(\mathrm{M}+$ $2 \mathrm{H})^{2+}$ species at respectively $\mathrm{m} / z 1141.8$ and 571.9 . Table 1 summarizes the intensity observed on the mass spec-

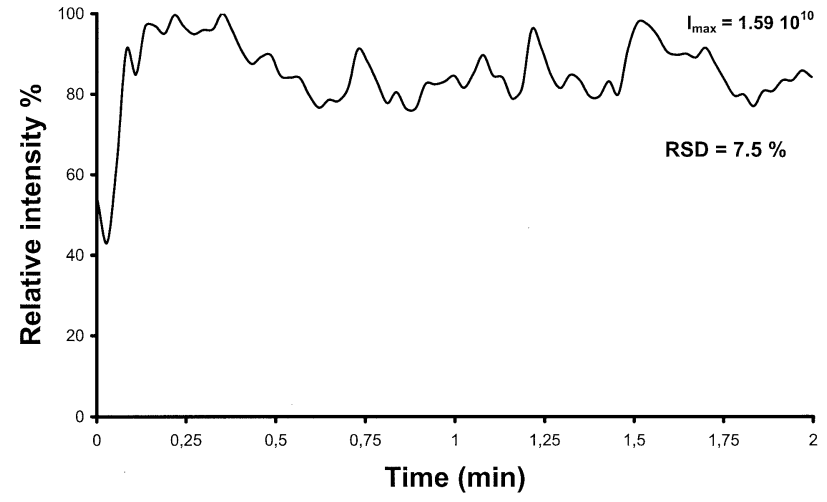

Figure 3. Total ion current signal recorded over a period of $2 \mathrm{~min}$ using a Gramicidin S sample at $20 \mu \mathrm{M}$ under a $\mathrm{HV}$ value of $2.2 \mathrm{kV}$.

tra and the relative intensity ratio measured for these species under a variety of conditions. We saw two main trends when the concentration decreases: (1) The TIC signal intensity increases and (2) the intensity ratio observed for the $(\mathrm{M}+\mathrm{H})^{+}$and $(\mathrm{M}+2 \mathrm{H})^{2+}$ species decreases. When the voltage value and the concentration were decreased, the micro-nib tip was moved closer to the MS inlet to observe a Taylor cone. In these conditions, the flow rate is increased and the spray is formed in a higher temperature region, as the ion trap inlet capillary is heated. The pattern of the resulting mass spectra is reminiscent of spectra recently obtained in APCI conditions without any corona discharge [11]. In addition, the concentration decrease from 20 to $1 \mathrm{mM}$ results in a slight increase of the solution organic content from 40 to $50 \%$; this may explain both that the signal intensity for the diluted solutions is slightly higher and that the intensity ratio observed for the $(\mathrm{M}+$ $\mathrm{H})^{+}$and $(\mathrm{M}+2 \mathrm{H})^{2+}$ species is lower as the $(\mathrm{M}+2 \mathrm{H})^{2+}$ species reacts with water vapor to give the $(\mathrm{M}+\mathrm{H})^{+}$ ion [12].

Table 1. Intensity of the TIC signal and relative intensity ratio observed for the $(\mathrm{M}+\mathrm{H})^{+}$and $(\mathrm{M}+2 \mathrm{H})^{2+}$ species of Gramicidin $\mathrm{S}$ observed during testing of the nib sources. Mass spectra plotted as an average after 2 min acquisition of the signal

\begin{tabular}{cccccc}
\hline Entry & $\begin{array}{c}\text { Gramicidin S } \\
\text { concentration }\end{array}$ & $\begin{array}{c}\mathrm{HV} \text { value } \\
(\mathrm{kV})\end{array}$ & $\begin{array}{c}\text { TIC relative } \\
\text { intensity }^{\mathrm{a}, \mathrm{b}}\end{array}$ & $\begin{array}{c}\text { Mass spectrum } \\
\text { intensity }^{\mathrm{a}, \mathrm{c}}\end{array}$ & $\begin{array}{c}(\mathrm{M}+\mathrm{H})^{+} /(\mathrm{M}+2 \mathrm{H})^{2+} \\
\text { intensity ratio }^{\mathrm{a}}\end{array}$ \\
\hline \hline 1 & $50 \mu \mathrm{M}$ & 2.5 & 1 & 1 & 1.2 \\
2 & $50 \mu \mathrm{M}$ & 2.2 & 1.1 & 1.1 & 1.2 \\
3 & $50 \mu \mathrm{M}$ & 2 & 1.6 & 1.2 & 1.2 \\
4 & $20 \mu \mathrm{M}$ & 2.5 & 3.9 & 1.9 & 0.92 \\
5 & $20 \mu \mathrm{M}$ & 2.2 & 5.0 & 3.4 & 0.87 \\
6 & $20 \mu \mathrm{M}$ & 2 & 5.0 & 3.4 & 0.87 \\
8 & $5 \mu \mathrm{M}$ & 2.2 & 7.8 & 17.4 & 0.50 \\
9 & $5 \mu \mathrm{M}$ & 2 & 8.8 & 11.8 & 0.45 \\
10 & $5 \mu \mathrm{M}$ & 1.8 & 7.8 & 10.5 & 0.29 \\
11 & $1 \mu \mathrm{M}$ & 1.8 & 13.2 & 23.0 & 0.37 \\
12 & $1 \mu \mathrm{M}$ & 1.5 & 7.9 & 8.8 & 0.45 \\
\hline
\end{tabular}

a Values determined with a precision better than $\pm 10 \%$ based on RSD value and on replicated experiments.

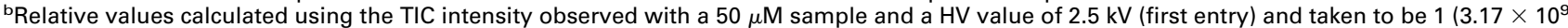
measured value).

${ }^{\mathrm{c}}$ Relative values calculated using the MS intensity observed with a $50 \mu \mathrm{M}$ sample and a HV value of $2.5 \mathrm{kV}$ (first entry) and taken to be 1 (1.78 $\times 10^{7}$ measured value). 


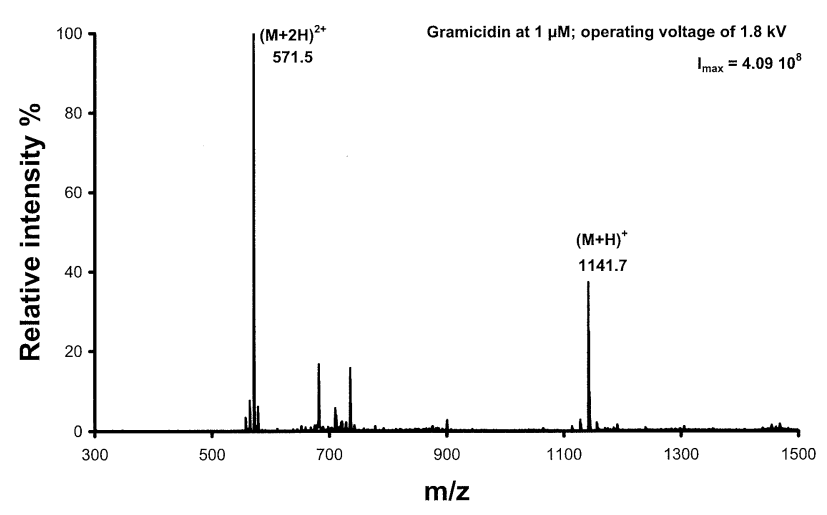

Figure 4. Mass spectrum using a Gramicidin S sample at $1 \mu \mathrm{M}$ under a $\mathrm{HV}$ value of $1.8 \mathrm{kV}$.

\section{Comparison with a Protana Nano-ESI Tip}

The performances of the nib-like sources were compared with those of a commercial nanoESI tip (Protana) (Gramicidin S at $1 \mu \mathrm{M}, \mathrm{HV}$ of $1 \mathrm{kV}$ ). First, the distance between the tip and the MS inlet is large compared with the case of the nib tip and the standard tips are operated at a lower voltage. Nonetheless, the intensity of the spectra is much the same for both types of tips. Another difference is the intensity ratio for the $(\mathrm{M}+\mathrm{H})^{+}$and $(\mathrm{M}$ $+2 \mathrm{H})^{2+}$ species; the spectrum obtained with a Protana tip only presents the $(\mathrm{M}+2 \mathrm{H})^{2+}$ species at $m / z 571.6$, as both $(\mathrm{M}+\mathrm{H})^{+}$and $(\mathrm{M}+2 \mathrm{H})^{2+}$ species are detected using a micro-nib. This reflects the difference in the source dimensions and flow rate [13, 14].

\section{Functioning Limits of the Nib-Like Sources}

Using a sample at $10 \mu \mathrm{M}$, the voltage was thus decreased from 1.8 to $1.2 \mathrm{kV}$ without any marked decrease either on the TIC signal intensity or on the mass spectrum intensity once the micronib optimal position had been found in the MS inlet. We finally tested a $1 \mu \mathrm{M}$ Gramicidin S solution with a HV supply of 1.5 and 1.8 $\mathrm{kV}$ (see Table 1). Figure 4 presents the spectrum obtained at $1 \mu \mathrm{M}$ under a $1.8 \mathrm{kV} \mathrm{HV}$. There is a group of peaks around $\mathrm{m} / \mathrm{z} 700$ that can not be attributed to Gramicidin S. Nonetheless, these peaks were not detected when another solution (blank or other peptide) was run; this indicates that they are not attributable to any SU-8 release.

\section{Conclusion}

We have demonstrated that the fabrication of nib-like sources is a promising route for designing novel nanoESI tips. Such sources are easier to load than standard emitter tips because of their 2-D topology and are thus compatible with the use of robotics in view of analysis automation. We have fabricated and tested prototypes using the resist SU-8. They present a relatively wide opening slot (around $20 \mu \mathrm{m} \times 30 \mu \mathrm{m}$ ) compared with standard nano-tips which have an i.d. of $1-5 \mu \mathrm{m}$ at their tip. This difference in the aperture size is reflected by the mass spectra pattern in terms of intensity ratio for the different charge states. The micronib optimal functioning is with a $1.8 \mathrm{kV} \mathrm{HV}$ supply and samples at $5-10 \mu \mathrm{M}$. The design and features of nib-like sources will now be improved so as to enhance their performances for MS applications.

\section{Acknowledgments}

The authors thank the French network for micro- and nanotechnologies for its financial support for this work (Integrated Proteomics project) as well as the GenHomme network (BioChipLab consortium). The Mass Spectrometry facility used for this study is funded by the European community (FEDER), the Région NordPas de Calais (France), the CNRS and the Université des Sciences et Technologies de Lille. The authors also thank Christophe Boyaval from IEMN for the SEM photographs and Adeline Page from the Mass Spectrometry Facility for her help with the ion trap mass spectrometer.

\section{References}

1. Lin, L.; Pisano, A.P. Silicon Processed Microneedles. IEEE J. Mictroelectromech. Syst. 1999, 8, 78-84.

2. Licklider, L.; Wang, X-Q.; Desai, A.; Tai, Y-C.; Lee, T. D. A Micromachined Chip-Based Electrospray Source for Mass Spectrometry. Anal. Chem. 2000, 72, 367-375.

3. Schultz, G. A.; Corso, T. N.; Prosser, S. J.; Zhang, S. A Fully Integrated Monolithic Microchip Electrospray Device for Mass Spectrometry. Anal. Chem. 2000, 72, 4058-4063.

4. Sjoedahl, J.; Melin, J.; Griss, P.; Emmer, A.; Stemme, G.; Roeraade, J. Characterization of Micromachined Hollow Tips for Two-Dimensional Nanoelectrospray Mass Spectrometry. Rapid Commun. Mass Spectrom. 2003, 17, 337-341.

5. Tang, K.; Lin, Y.; Matson, D. W.; Kim, T.; Smith, R. D. Generation of Multiple Electrosprays Using Microfabricated Emitter Arrays for Improved Mass Spectrometric Sensitivity. Anal. Chem. 2001, 73, 1658-1663.

6. Kameoka, J.; Orth, R.; Ilic, B.; Czaplewski, D.; Wachs, T.; Craighead, H. G. An Electrospray Ionization Source for Integration with Microfluidics. Anal. Chem. 2002, 74, 5897-5901.

7. Yuan, C. H.; Shiea, J. Sequential Eelectrospray Analysis Using Sharp-Tip Channels Fabricated on a Plastic Chip. Anal. Chem. 2001, 73, 1080-1083.

8. Kim, J. S.; Knapp, D. R. Microfabricated PDMS Multichannel Emitter for Electrospray Ionization Mass Spectrometry. J. Am. Soc. Mass Spectrom. 2001, 12, 463-469.

9. Kim, J. S.; Knapp, D. R. Miniaturized Multichannel Electrospray Ionization Emitters on Polydimethylsiloxane Microfluidic Devices. Electrophoresis 2001, 22, 3993-3999.

10. Rossier, J. S.; Youhnovski, N.; Lion, N.; Damoc, E.; Becker, S.; Reymond, F.; Girault, H. H.; Przybylski, M. Thin-Chip Microspray System for High-Performance Fourier-Transform IonCyclotron Resonance Mass Spectrometry of Biopolymers. Angew. Chem. Int. Ed. 2003, 42, 53-58.

11. Cristoni, S.; Bernardi, L. R.; Biunno, I.; Guidugli, F. Analysis of Peptides Using Partial (No Discharge) Atmospheric Pressure Chemical Ionization Conditions with Ion Trap Mass Spectrometry. Rapid Commun. Mass Spectrom. 2002, 16, 1686-1691.

12. Zhan, D.; Fenn, J. B. Gas Phase Hydration of Electrospray Ions from Small Peptides. Int. J. Mass Spectrom. 2002, 219, 1-10.

13. Wilm, M. S.; Mann, M. Analytical Properties of the Nanoelectrospray Ion Source. Anal. Chem. 1996, 68, 1-8.

14. Schmidt, A.; Karas, M.; Dulcks, T. Effect of Different Solution Flow Rates on Analyte Ion Signals in Nano-ESI MS, or: When Does ESI Turn into Nano-ESI? J. Am. Soc. Mass Spectrom. 2003, $14,492-500$. 